GAPP, número 23, mayo-octubre de 2020

Sección: ESTUDIOS

Recibido: 17-07-2019

Modificado: 07-11-2019

Aceptado: 07-11-2019

DOI: 10.24965/gapp.i23.10699

Páginas: 45-63

\title{
Estrategias para el fortalecimiento de las autoridades auxiliares del municipio en Sinaloa, México
}

\section{Strategies for strengthening the auxiliary authorities of the municipality in Sinaloa, Mexico}

Raúl Portillo Molina

Universidad Autónoma de Occidente (México) ORCIS: https://orcid.org/0000-0003-4756-4981

raul.portillo@udo.mx

\section{NOTA BIOGRÁFICA}

Doctor en Estudios Fiscales por la Universidad Autónoma de Sinaloa, incorporado al PNPC del Conacyt. PTC Investigador de la Universidad Autónoma de Occidente, Unidad Regional Guasave, Sinaloa, México e integrante del Sistema Nacional de Investigadores del CONACyT (Candidato a Investigador Nacional) y del Instituto de Apoyo a la Investigación e Innovación (INAPI) del estado de Sinaloa. Línea de investigación: Federalismo fiscal y finanzas públicas.

Julio César Rodríguez Valdez

Universidad Autónoma de Occidente (México) ORCID: https://orcid.org/0000-0002-1852-4916 jcrvaldez59@gmail.com

\section{NOTA BIOGRÁFICA}

Doctor en Estudios Fiscales por la Universidad Autónoma de Sinaloa, incorporado al PNPC del Conacyt. PTC investigador de la Universidad Autónoma de Occidente, Unidad Regional Guasave, Sinaloa, México e integrante del Instituto de Apoyo a la Investigación e Innovación (INAPI) del estado de Sinaloa. Línea de investigación: Sistema tributario y finanzas públicas.

Daniel García Urquidez

Universidad Autónoma de Occidente (México) ORCID: https://orcid.org/0000-0002-2066-8329 dgarciau65@gmail.com

\section{NOTA BIOGRÁFICA}

Doctor en ciencias sociales por la Universidad Autónoma Metropolitana, Unidad Xochimilco, incorporado al PNPC del Conacyt; PTC investigador de la Universidad Autónoma de Occidente, Unidad Regional Guasave, Sinaloa, México e integrante del Instituto de Apoyo a la Investigación e Innovación (INAPI) del estado de Sinaloa. Línea de investigación: Planeación estratégica y gobiernos locales.

\section{RESUMEN}

En la investigación se analizan los rezagos que padecen las poblaciones que existen al interior de los municipios en el estado de Sinaloa, México, que en buena medida son producto de las prácticas 
centralistas de gobierno de las autoridades municipales. Se muestran áreas de oportunidad para el diseño de políticas públicas que les otorguen autonomía en decisiones políticas y manejo de recursos en beneficio de los habitantes que legalmente representan. La investigación tiene un enfoque cuantitativo, no experimental, y encaja en la modalidad de exploratoria-descriptiva, utilizando el cuestionario como técnica de recopilación de la información estructurado con preguntas cerradas que se aplicó a 120 habitantes utilizando el muestro aleatorio simple. Se concluye que la asociación entre sindicaturas, como primera estrategia y la fusión como la segunda, serían estrategias innovadoras que podrían fortalecer su capacidad de gestión, además se descarta que la municipalización de sindicaturas sea el mejor camino a seguir. Se propone adicionalmente la creación de un sistema municipal de coordinación fiscal que promueva los principios de justicia y equidad distributiva entre las autoridades auxiliares de los municipios de Sinaloa.

\title{
PALABRAS CLAVE
}

Fortalecimiento municipal; autoridades auxiliares del municipio; asociación de municipios; fusión municipal; intermunicipalización.

\begin{abstract}
The investigation analyzes the lags suffered by the populations that exist within the municipalities in the state of Sinaloa, Mexico, which are largely a product of the centralist government practices of the municipal authorities. Areas of opportunity are shown for the design of public policies that grant them autonomy in political decisions and resource management for the benefit of the inhabitants they legally represent. The research has a quantitative, non-experimental approach, and fits into the exploratorydescriptive modality, using the questionnaire as a technique for collecting structured information with closed questions that was applied to 120 inhabitants using simple random sampling. It is concluded that the association between trade unions, as the first strategy and the merger as the second, would be innovative strategies that could strengthen their management capacity, and it is ruled out that the municipalization of trade unions is the best way forward. The creation of a municipal tax coordination system that promotes the principles of justice and distributive equity among the auxiliary authorities of the municipalities of Sinaloa is also proposed.
\end{abstract}

\section{KEYWORDS}

Municipal strengthening; auxiliary authorities of the municipality; association of municipalities; municipal merger; intermunicipalization.

\section{SUMARIO}

1. INTRODUCCIÓN. 2. MATERIALES Y MÉTODOS. 3. ANTECEDENTES. 4. DISMINUCIÓN DE MUNICIPALIDADES (FUSIÓN): TENDENCIA MUNDIAL. 5. ASOCIACIÓN DE MUNICIPIOS. 6. RESULTADOS. CONCLUSIONES. REFERENCIAS BIBLIOGRÁFICAS.

\section{INTRODUCCIÓN}

El estudio se realiza en el estado de Sinaloa, ubicado en el Noroeste de México. La entidad cuenta con un extenso y fértil valle agrícola que la ubica como la principal productora de alimentos a escala nacional. A eso se suma el primer lugar que ocupa en el país tanto en producción ganadera como por el valor de la pesca y la acuacultura. En los últimos lustros han avanzado el turismo ${ }^{1}$ y la industrialización, pero se reconoce la necesidad de modificar el agotado modelo económico sustentado en el sector primario, principalmente en la agricultura, en aras de lograr una economía más próspera y competitiva que se base en la innovación, la sustentabilidad, la ciencia y la tecnología, según se establece en el Plan Estatal de Desarrollo 2017-2021 (Gobierno del Estado de Sinaloa, 2017).

1 El puerto de Mazatlán, ubicado al sur del estado es uno de los principales destinos turísticos del país con una oferta de 9,552 habitaciones. Sinaloa cuenta con $656 \mathrm{~km}$ de litoral con numerosas playas y bahías. 
Mapa 1. Ubicación de la Sindicatura de Juan José Ríos

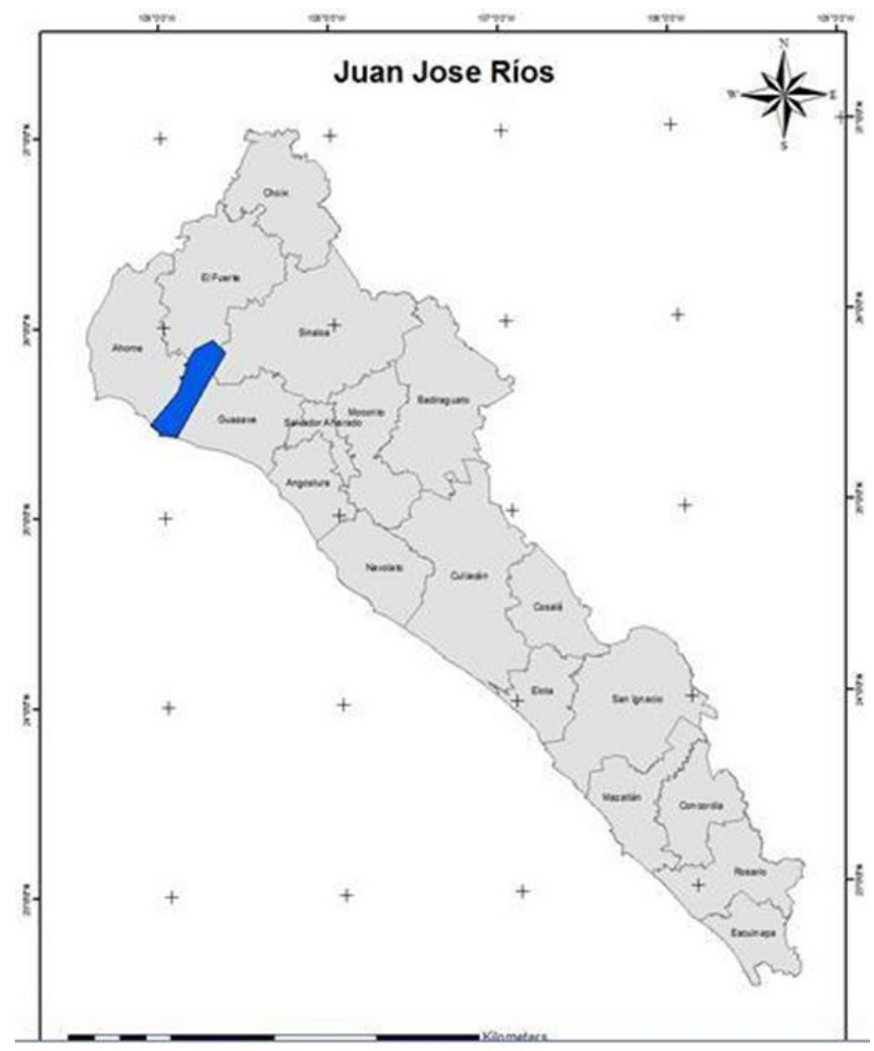

Fuente: https:/juanjoseriosmunicipio.wordpress.com/2013/04/01/ubicacion-municipio-juan-jose-rios/ (2013)

El propósito central del estudio se encaminó a evaluar la capacidad de autogestión de la sindicatura de Juan José Ríos, del municipio de Guasave ${ }^{2}$, y elaborar un diagnóstico de la cobertura y la calidad de los servicios públicos que son prestados directamente por la autoridad municipal. Se escogió esta sindicatura porque es cuna de uno de los movimientos pro municipalización más constantes del estado de Sinaloa. Los habitantes de esa población tienen décadas luchando por convertirse en el municipio número 19 de Sinaloa, esgrimiendo como bandera política el abandono en el que los ha sumido la falta de atención del gobierno municipal. El estudio pulsa también el grado de aceptación y apoyo ciudadano para lograr el objetivo de convertirse en un nuevo municipio ${ }^{3}$.

La sindicatura de Juan José Ríos se encuentra en la parte noroeste del municipio de Guasave. Está ubicada en el norte del estado de Sinaloa, en la región del Valle del Fuerte, a $20 \mathrm{~km}$ al sur de la ciudad de Los Mochis, $43 \mathrm{~km}$ al norte de Guasave y a $208 \mathrm{~km}$ al norte de Culiacán, la capital del estado. La cabecera de la sindicatura es la ciudad de nombre homónimo y es considerada la séptima ciudad de la entidad.

Esta sindicatura registra una extensión de 960.24 hectáreas, ocupa el $27.71 \%$ de la superficie total del municipio de Guasave, siendo así, la segunda sindicatura más grande, sólo es superara por la sindicatura Central de la ciudad de Guasave. Actualmente geográficamente se divide en las comisarías de Bachoco y Ejido Campo 38. Tiene una población total de 23,553 habitantes (INEGI, 2010).

En ese sentido, a lo largo del texto se expone la necesidad de crear mecanismos que permitan mejorar las condiciones de vida de las poblaciones que existen al interior de los municipios. Cabe señalar que México

2 Guasave es uno de los 18 municipios de Sinaloa. Su vocación económica es primordialmente agrícola, con incipiente desarrollo de su industria y sector de servicios.

3 En el texto de la Constitución Política del Estado de Sinaloa de 1917 se oficializó la división política del estado en dieciséis municipios. En febrero de 1962 se aprueba la creación del municipio de Salvador Alvarado, el número 17, y en agosto de 1983 Navolato se constituye en el municipio número 18. Hasta la fecha el estado de Sinaloa se divide en 18 municipios, sin embargo, existen diversas comunidades que exigen convertirse en municipios para tener acceso a mayores recursos públicos. 
es una república federal, dividida en 32 estados que en conjunto tienen 2,457 municipios (INEGI, 2015). La Constitución Política de México reconoce solo tres niveles de gobierno (federación, estados y municipios) y las formas embrionarias o precarias de gobierno dentro de los municipios reciben el nombre genérico de autoridades auxiliares, que en el caso de Sinaloa se reconocen como sindicaturas y comisarías (Congreso del Estado de Sinaloa, 2016) ${ }^{4}$.

De igual forma, como objetivo complementario, se visualizaron nuevas estrategias para el fortalecimiento financiero de la sindicatura de Juan José Ríos. En resumen, la importancia de este estudio afianzó la posibilidad de conocer las posturas de los habitantes del medio rural para transitar hacia el proceso de consolidar su fortalecimiento y desarrollo socioeconómico.

En México existe abundante literatura y proclamas en torno a la necesidad de descentralizar atribuciones y recursos a los municipios para fortalecer su ejercicio como primer nivel de gobierno, pero extrañamente son pocas las investigaciones que abordan la necesidad de dotar de mayores capacidades a las modalidades de gobierno que perviven en el territorio municipal. Paradójicamente los municipios son escenarios del fenómeno centralista, que tanto han combatido a nivel nacional (García, 2009).

La creación del Sistema Nacional de Coordinación Fiscal en 1980 y diversas reformas en los últimos lustros al Artículo 115 de la Constitución Política del país (que delimita las facultades y obligaciones de los municipios) prueban que en México se ha legislado para tratar de fortalecer la capacidad de gestión del ámbito de gobierno más cercano a la población.

En ese contexto, se otorgaron facultades a los Ayuntamientos para la recaudación directa de algunos impuestos de carácter municipal, entre ellos el predial, y simultáneamente, se le asignaron más atribuciones en materia de prestación de servicios públicos. Sin embargo, la ampliación de facultades no ha sido acompañada de los recursos suficientes para hacer frente a las nuevas responsabilidades, situación que como se verá más adelante impacta directamente a los ciudadanos de su jurisdicción y tiene a numerosos municipios sumergidos o al borde de crisis financieras.

Sin embargo, Díaz (2002) afirma tajantemente que el principal problema del federalismo mexicano son los gobiernos estatales y municipales ya que estos gastan como si fueran gobiernos autoritarios, destinando los recursos a quienes más capacidad de presión tienen, sin tomar en cuenta a los ciudadanos que contribuyen.

Para Romo y Chauca (2007) el principal problema que ha tenido que enfrentar el federalismo, es la diferencia en el grado de desarrollo de estados y municipios, dado que mientras unos buscan ser más competitivos, otros más quieren seguir dependiendo enormemente del centro para cumplir con las responsabilidades que les han sido asignadas por mandato legal.

A raíz de las reformas constitucionales y la creación de fondos de apoyo a los municipios, esta instancia de gobierno cuenta con una mayor capacidad de gestión y atención en materia de obras y servicios públicos. Si bien, se registran avances que saltan a la vista, no se puede soslayar que las demandas sociales de los habitantes del medio rural están transitando más rápidamente que esos cambios que se han presentado.

La añeja aspiración de hacer del municipio un actor protagónico del desarrollo aún enfrenta barreras que difícilmente podrán superarse si los municipios carecen de autonomía financiera, tema que debe resolverse mediante una reforma política de gran calado en el país, pero también de acciones y proyectos que deben emanar de las entidades federativas y los propios municipios. Desde estas instancias deben diseñarse y ejecutarse fórmulas imaginativas que permitan despertar el enorme potencial oculto que subyace en las autoridades auxiliares o comunidades que hasta hoy cuentan con una muy pobre participación de sus habitantes, en buena medida por la falta de estrategias y programas que alienten esquemas de autogobierno.

En ese sentido, Arellano, Cabrero, Montiel y Aguilar (2011) afirman que los gobiernos locales son el eslabón más débil del federalismo mexicano. En ese tenor López, Ayala y Arellanes (2017) sostienen que en México los gobiernos locales se enfrentan a diversos conflictos como la insuficiencia de recursos presupuestales y limitación de capacidades técnicas, que les impiden alcanzar un desarrollo de manera eficaz y eficiente.

Es necesario pensar en un cambio que abarque distintos factores; es indispensable llevar a cabo reformas sustantivas de carácter radical para el mejoramiento de las instancias locales y si estas emanan desde el interior del mismo municipio, se empezarán a romper paradigmas federalistas que señalan que el desarrollo y crecimiento social y económico de las localidades solo son viables mediante acciones de arriba hacia abajo.

4 El Artículo 11 de la Ley de Gobierno Municipal de Sinaloa establece lo siguiente: «Los municipios se dividirán en sindicaturas y éstas en comisarías, cuya extensión y límites los determinarán los Ayuntamientos con la ratificación del Congreso del Estado». 


\section{MATERIALES Y MÉTODOS}

La investigación se realizó con un enfoque cuantitativo, no experimental y por su tipo se ubica en la modalidad exploratoria-descriptiva y correlacional, al atender las características de un fenómeno poco estudiado, cómo lo es el fortalecimiento integral de las autoridades auxiliares de los municipios de Sinaloa. Adicionalmente, se hizo un análisis entre variables al medir la variación de una (dependiente) en base al comportamiento de la otra (independiente) (Hernández, Fernández y Baptista, 2006; Salkind, 1999).

El Instituto Nacional de Estadística y Geografía (INEGI, 2010) registró una población total de 285,912 habitantes en el municipio de Guasave, diseminados en 543 localidades. La población de estudio considera solamente los habitantes de la localidad de Juan José Ríos, que según cifras del mismo censo poblacional registró una población de 23,553 habitantes, de los cuales 15,600 superan los 18 años de edad. Se tomó la decisión de encuestar solo a personas de 18 años o más, considerando que a esa edad se alcanza la ciudadanía en México y es previsible que tengan un juicio formado sobre el asunto que se estudia.

La determinación de una muestra representativa tiene como objetivo no analizar o trabajar con todos los elementos de la población o universo de estudio sino sólo con una parte o fracción de ella. Tomando como base el tamaño del universo de la investigación y haciendo uso de la formula diseñada por SierraBravo (1988), con una confianza del $90 \%$, un error del $7.5 \%$ y probabilidad éxito del $50 \%$ se proyectó una muestra de 120 encuestados, las cuales se seleccionaron de manera probabilística aleatoria simple.

En relación a la edad y sexo de los encuestados, el $52.5 \%$ fueron del sexo femenino. El rango de edad de mayor frecuencia se ubicó entre los 20 y 29 años, esto al contabilizar $30.8 \%$ de la población de estudio en donde su mayoría fueron féminas y el $12.5 \%$ superaron los 60 años de edad de los cuales el $40 \%$ fueron hombres.

FIgURA 1. ANÁLISIS DESCRIPTIVO DE LA MUESTRA, POR SEXO Y RANGO DE EDAD

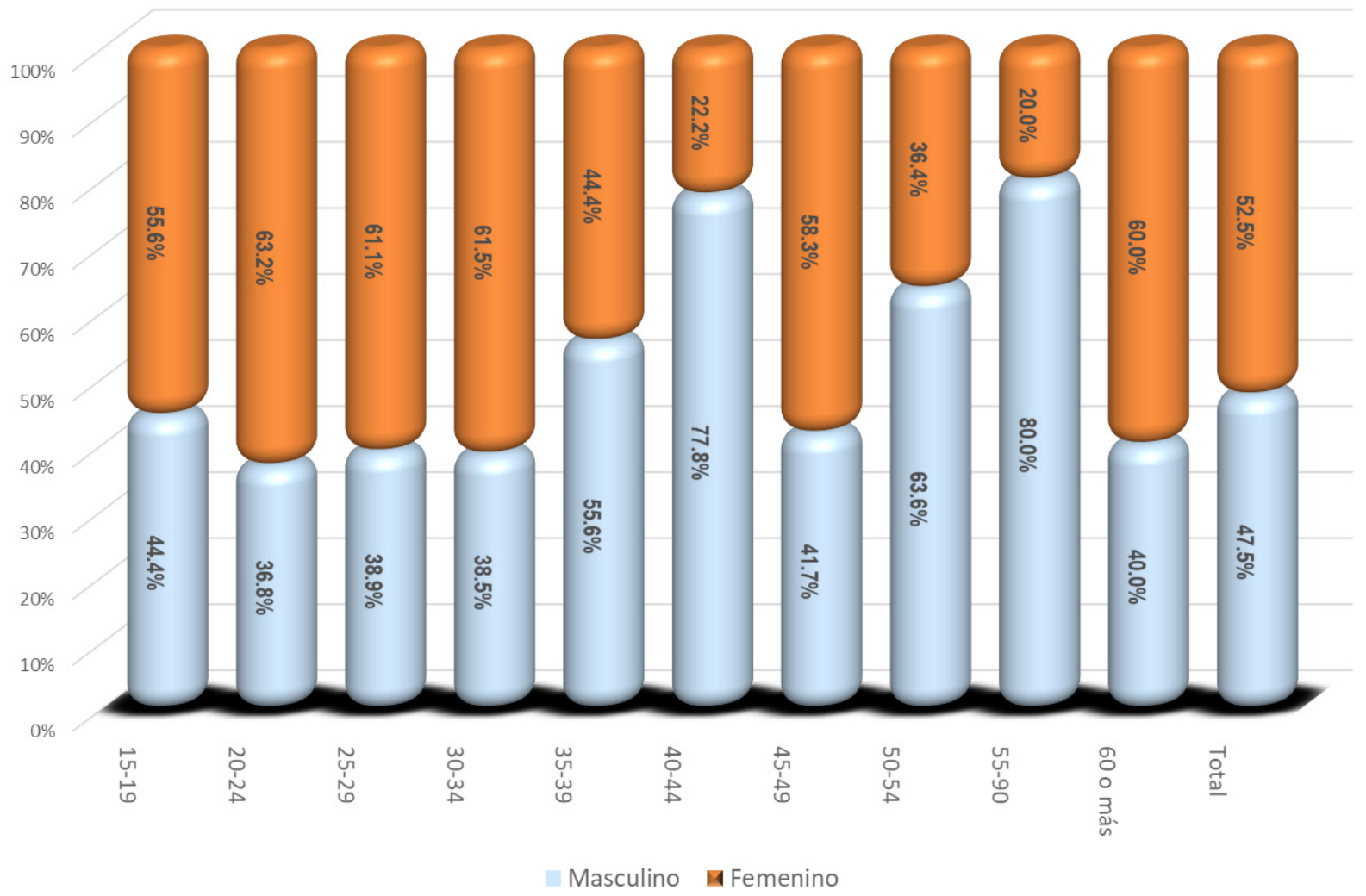

Fuente: Elaboración propia. @ Portillo M., Raúl; Rodríguez V., Julio César y García U., Daniel.

En relación a la ocupación el $43.3 \%$ de la muestra señaló que se desempeñaba como empleado dentro de la misma comunidad, el $21.7 \%$ señaló ser empresario y solo el $5.0 \%$ refirió no estar ocupado en ese momento de la encuesta. 
GAPP. Nueva Época - N. ${ }^{2}$ 23, mayo-octubre 2020 - ISSN: 1989-8991 - DOI: 10.24965/gapp.i23.10699 - [Págs. 45-63]

Estrategias para el fortalecimiento de las autoridades auxiliares del municipio en Sinaloa, México Raúl Portillo Molina / Julio César Rodríguez Valdez / Daniel García Urquidez

TABLA 1. OCUPACIÓN DE LOS SUJETOS DE ESTUdio

\begin{tabular}{lr}
\hline & Porcentaje \\
\hline Estudiante & 18.3 \\
\hline Empleado & 43.3 \\
\hline Empresario & 21.7 \\
\hline Ama de casa & 10.1 \\
\hline Jubilado & 1.7 \\
\hline Sin ocupación & 5.0 \\
\hline Total & 100.0 \\
\hline
\end{tabular}

Fuente: Elaboración propia. @ Portillo M., Raúl; Rodríguez V., Julio César y García U., Daniel.

La objetividad de los resultados la podríamos medir en relación al nivel de estudios de los encuestados, esto debido a que el $44.20 \%$ manifestó tener estudios de licenciatura, el $2.5 \%$ estudios de posgrado y el $25.8 \%$ cursó estudios de bachillerato. Solamente el $3.3 \%$ indicó no haber estudiado.

Como complemento a la objetividad de los resultados, del total de empleados encuestados el $44.20 \%$ afirmó tener estudios de licenciatura y casi el $27 \%$ de bachillerato. En ese mismo sentido, de los empresarios atendidos, el $46.20 \%$ contaba con estudios de licenciatura y más del $30 \%$ con nivel medio superior.

Para efectos de esta investigación, el enfoque cuantitativo se justificó por la complejidad de la problemática planteada, así como la orientación que se presentó para su comprensión, al querer demostrar la mejor estrategia para el fortalecimiento del medio rural del municipio sinaloense y entender las inquietudes de los habitantes de la sindicatura de Juan José Ríos, que busca su independencia hacia la municipalización, dicha justificación marcó la pauta para retomar la recopilación de la información haciendo uso de un cuestionario en su mayoría con preguntas cerradas de opción múltiple y dicotómicas.

\section{ANTECEDENTES}

En relación a los requisitos para la creación de nuevos municipios en México, Lugo (2010) expone que los factores más importantes son la capacidad financiera, infraestructura, población, territorio y opinión de los ayuntamientos. Observó que existen limitantes e imprecisiones en las constituciones estatales y que los procesos de municipalización están condicionados a intereses políticos. Clarifica que se han constituido nuevos municipios con escasa sustentabilidad financiera por lo que reconoce que antes de iniciar los procesos de municipalización se deben de fortalecer la gestión institucional, los marcos jurídicos y una mayor participación social en los asuntos públicos.

Cadena, Franco y Campos (2007) identifican como requisitos fundamentales para la creación de nuevas municipalidades la disponibilidad de recursos que garanticen la autosuficiencia económica, la existencia de un rango de población y contar con la anuencia de los municipios afectados. En su investigación analizan el marco legal de cada entidad para la creación de nuevos municipios e identifican 27 requisitos generales en el conjunto de las 31 entidades federativas de México, siendo el estado de Tlaxcala el que considera mayor número de requerimientos, mientras Nuevo León establece únicamente dos.

Por citar un ejemplo, la Constitución Política del Estado de Sonora señala como requisitos para la creación de un nuevo municipio una población superior a los diez mil habitantes, contar con elementos para proveer a su existencia política, de igual forma, que se conceda al ayuntamiento o ayuntamientos afectados el derecho de ser oído dentro del término de dos meses y que se oiga sobre el particular al Ejecutivo del Estado; y que la creación del nuevo municipio sea aprobada por las dos terceras partes de los miembros del Congreso (Congreso del Estado de Sonora, 2015).

De igual forma, Ilaman la atención los requisitos en el estado de Tlaxcala, ya que difiere a los de otras entidades, al exigir un padrón de contribuyentes de obligaciones fiscales municipales y el cumplimento de cuando menos las dos terceras partes de los contribuyentes en sus obligaciones fiscales municipales, esta- 
GAPP. Nueva Época - N. ${ }^{\circ}$ 23, mayo-octubre 2020 - ISSN: 1989-8991 - DOI: 10.24965/gapp.i23.10699 - [Págs. 45-63]

Estrategias para el fortalecimiento de las autoridades auxiliares del municipio en Sinaloa, México

Raúl Portillo Molina / Julio César Rodríguez Valdez / Daniel García Urquidez

tales y federales (Congreso del Estado de Tlaxcala, 2015). Adicionalmente, esta entidad solicita la anuencia de las dos terceras partes de los ciudadanos empadronados en el registro federal de electores del Instituto Nacional Electoral (INE) y que habiten en el municipio o municipios involucrados; ser autosuficiente económicamente y contar con la infraestructura básica de los servicios establecidos en el Artículo 115 Fracción III ${ }^{5}$ de la Constitución Política de los Estados Unidos Mexicanos, entre otros requisitos (Congreso de la Unión, 2015).

En Sinaloa, la Fracción VII del Artículo 43 de la Constitución Política del Estado, faculta al Congreso local para la creación de nuevas municipalidades dentro de los límites de las ya existentes, condicionándolas a una población de 30 mil habitantes y que se compruebe que tienen los elementos para proveer a su existencia política, de igual forma, deberá tener la aprobación de las dos tercera partes de los Diputados del Congreso del Estado y la aceptación de 10 Ayuntamientos que actualmente existen en la entidad.

En México no cesa la creación de nuevos municipios. De acuerdo a Preciado (2009) de 1970 al 2006 se constituyeron 74 nuevos municipios -en las décadas de los 70's y 80 's se crean 21 municipios y en la siguiente década hasta el 2006, se formalizaron 53 municipalidades más- en el país. Por su parte el INEGI (2017) reporta un incremento de 60 nuevos municipios de 1989 al 2017 y registra una suma total de 2,447 municipios en todo el territorio nacional.

TABLA 2. MUNICIPIOS POR ENTIDAD FEDERATIVA 2017/P

\begin{tabular}{|c|c|c|c|}
\hline Entidad & N. ${ }^{\circ}$ de Municipios & Entidad & N. ${ }^{\circ}$ de Municipios \\
\hline Total nacional & & & 2,447 \\
\hline Aguascalientes & 11 & Morelos & 33 \\
\hline Baja California & 5 & Nayarit & 20 \\
\hline Baja California Sur & 5 & Nuevo León & 51 \\
\hline Campeche & 11 & Oaxaca & 570 \\
\hline Coahuila de Zaragoza & 38 & Puebla & 217 \\
\hline Colima & 10 & Querétaro & 18 \\
\hline Chiapas & $123^{/ 1}$ & Quintana Roo & 11 \\
\hline Chihuahua & 67 & San Luis Potosí & 58 \\
\hline Durango & 39 & Sinaloa & 18 \\
\hline Guanajuato & 46 & Sonora & 72 \\
\hline Guerrero & 81 & Tabasco & 17 \\
\hline Hidalgo & 84 & Tamaulipas & 43 \\
\hline Jalisco & 125 & Tlaxcala & 60 \\
\hline México & 125 & Veracruz de Ignacio de la Llave & 212 \\
\hline Michoacán de Ocampo & 113 & Yucatán & 106 \\
\hline
\end{tabular}

Fuente: INEGI, 2017.

5 Los Municipios tendrán a su cargo las funciones y servicios públicos siguientes: a) Agua potable, drenaje, alcantarillado, tratamiento y disposición de sus aguas residuales; b) Alumbrado público; c) Limpia, recolección, traslado, tratamiento y disposición final de residuos; d) Mercados y centrales de abasto; e) Panteones; f) Rastro; g) Calles, parques y jardines y su equipamiento; h) Seguridad pública, en los términos del artículo 21 de esta Constitución, policía preventiva municipal y tránsito; en www.ordenjuridico.gob.mx i) Los demás que las Legislaturas locales determinen según las condiciones territoriales y socio-económicas de los Municipios, así como su capacidad administrativa y financiera. 
GAPP. Nueva Época - N. ${ }^{\circ}$ 23, mayo-octubre 2020 - ISSN: 1989-8991 - DOI: 10.24965/gapp.i23.10699 - [Págs. 45-63]

Estrategias para el fortalecimiento de las autoridades auxiliares del municipio en Sinaloa, México

Raúl Portillo Molina / Julio César Rodríguez Valdez / Daniel García Urquidez

Es muy probable que la cifra de 2,447 municipios reportada por el INEGI (2017) haya cambiado. En ese sentido, Bravo (2017) menciona que a nivel nacional existían 11 entidades federativas que analizaban la posibilidad de constituir 22 nuevos municipios, como se refleja en la Tabla 3:

TABLA 3. PROYECCIÓN DE NUEVOS MUNICIPIOS EN MÉXICO

\begin{tabular}{|c|c|c|}
\hline Entidad federativa & Nuevo Municipio & Segregado del municipio de: \\
\hline \multirow[t]{2}{*}{ Campeche } & Seybaplaya & Champotón \\
\hline & Sabancuy & Del Carmen \\
\hline \multirow[t]{3}{*}{ Baja California } & Isla Cedros & Ensenada \\
\hline & San Quintín & Ensenada \\
\hline & San Felipe & Ensenada \\
\hline \multirow[t]{3}{*}{ Zacatecas } & Pozo de Gamboa & N. D. \\
\hline & Tacoaleche & N. D. \\
\hline & Laguna Grande & Monte Escobedo \\
\hline \multirow[t]{2}{*}{ Guanajuato } & Santa Anita Pacueco & N. D. \\
\hline & San Juan Cerano & N. D. \\
\hline \multirow[t]{2}{*}{ Sonora } & Miguel Alemán & Hermosillo \\
\hline & Pueblo Yaqui & Cajeme \\
\hline \multirow[t]{5}{*}{ Tabasco } & Tecolutilla & Comalcalco \\
\hline & La Venta & Huimanguillo \\
\hline & Macultepec & Del Centro \\
\hline & Vicente Guerrero & Centla \\
\hline & El Triunfo & Balancán \\
\hline Nayarit & Islas Marías & San Blas \\
\hline Estado de México & San Juan Zitlaltepec & Zumpango \\
\hline Puebla & Chipilo & San Grego Atzompa \\
\hline Jalisco & Capilla de Guadalupe & Tepatitlán de Morelos \\
\hline \multirow[t]{2}{*}{ Sinaloa } & Juan José Ríos & Guasave \\
\hline & Eldorado/1 & Culiacán \\
\hline
\end{tabular}

Fuente: Elaboración propia en base a Bravo (2017).

En relación al estado de Sinaloa, García (2009) señala que sindicaturas y comisarías son niveles de gobierno en gestación, con autoridades elegidas en plebiscitos o asambleas, que cuentan con insignificantes recursos lo que representa un verdadero obstáculo para atender las demandas de sus pobladores. En ese mismo sentido, Portillo, Rodríguez, González y Vélez (2015) resumen que en Sinaloa existen sindicaturas que superan el número de habitantes de algunos municipios, tal es el caso de la de Benito Juárez, localizada en el municipio de Guasave, que en conjunto registra más de 36 mil habitantes, cantidad que supera a la registrada en cinco municipios de la entidad y no obstante, dicha sindicatura no recibe recursos directos por parte del Estado ni de la Federación, ni del propio municipio del que forma parte. 
Por citar un ejemplo, en el año 2016 el municipio de Concordia recibió más de 86.3 millones de pesos, Badiraguato 80.7, Cosalá 45.2, San Ignacio 47.8 y Choix 77.1, vía transferencias estatales y federales, en carácter de condicionadas y no condicionadas (ASE, 2016), mientras que las sindicaturas dependen totalmente de las obras y servicios que se decidan en el seno de los ayuntamientos.

Son numerosos los investigadores que han documentado el centralismo en la vida política y económica de México, pero ha pasado prácticamente inadvertido el centralismo que se ejerce el interior de los municipios. Las prácticas centralistas marcan una diferencia muy clara en la cobertura y calidad de los servicios públicos que se prestan en las cabeceras municipales, en detrimento de las condiciones de vida del resto de las poblaciones que forman parte de los municipios (García, 2009).

Esta situación se vive en Sinaloa, estado que cuenta con 18 municipios, debido a que no tiene dispositivos jurídicos que obliguen a los gobiernos locales a descentralizar o transferir con criterios de equidad y justicia parte de los recursos del erario municipal (Portillo et al, 2015).

En ese marco, Portillo et al. (2015), en un estudio realizado en el municipio de Guasave, dejan evidencia de la inequidad distributiva en las sindicaturas de los recursos provenientes del impuesto predial rústico que se dio en el periodo $2008-2010^{6}$, que, por la naturaleza del tributo, deberían ejercerse exclusivamente en el medio rural. En realidad, hasta hoy, los ayuntamientos disponen de esos recursos de manera discrecional, dado que no existe lineamiento alguno que regule la equidad y justicia distributiva de dicho gravamen municipal, sólo se ha legislado para que sea aplicado en el medio rural, pero sin brindar dispositivos legales que aseguren que los ingresos tengan como destino las comunidades rurales.

Lo anterior ha sido una situación poco estudiada, a pesar de la inconformidad que se incuba en las sindicaturas de la entidad. Y en muchos casos es más alto el número de personas que habitan fuera de la cabecera municipal ${ }^{7}$. Para ello vale la pena escudriñar un poco en el caso concreto de Guasave. Este municipio de acuerdo a cifras del INEGI (2010) tiene aproximadamente 285 mil habitantes, de los cuales un poco menos del $25 \%$, en promedio 71 mil habitantes, vive en la cabecera municipal, el resto lo hace en las más de 540 localidades que lo conforman. En su geografía existen dos poblaciones que rebasan los 20 mil habitantes, una más arriba de los 10 mil y otra que supera los cinco mil habitantes. Sin embargo, la cabecera municipal supera visiblemente a todas esas comunidades en cuanto a la cobertura y calidad de servicios públicos, sin que necesariamente sean óptimos.

Los movimientos políticos y sociales que promueven la creación del municipio número 19 del Estado de Sinaloa han transitado por más de dos décadas sin éxito alguno. A la fecha, solamente dos sindicaturas han solicitado formalmente al Congreso del Estado su conversión en municipios. Eldorado en Culiacán y Juan José Ríos en Guasave. Como antecedente, el Gobernador del Estado, Renato Vega Alvarado, presentó ante la LV Legislatura del Congreso del Estado, el 29 de septiembre de 1998, tres meses antes de que concluyera su administración y la de esa misma legislatura, el decreto de creación del Municipio de Eldorado. La propuesta fue rechazada el 18 de marzo del año siguiente por la nueva Legislatura (LVI).

La otra sindicatura que ha exigido su conversión en municipio, Juan José Ríos, del municipio de Guasave, se fundó como poblado rural debido a los desplazados de la presa Miguel Hidalgo en 1955 y no fue sino hasta el 13 de julio de 1989 que obtuvo el estatus de ciudad (Pérez, 2012). Los antecedentes legales para la municipalización de esta sindicatura surgen en la LVIII Legislatura, el 18 de julio de 2006, por parte de los Diputados integrantes del grupo parlamentario del Partido de la Revolución Democrática (PRD).

Dicho grupo avaló el proyecto de decreto para la creación del municipio número 19 del Estado de Sinaloa, denominándolo Juan José Ríos. En este se contemplaba agrupar a la propia sindicatura de Juan José Ríos, perteneciente al municipio de Guasave, más la porción de la ciudad de Juan José Ríos que actualmente pertenece al municipio de Ahome, más las localidades de Bachoco II, Ejido Cerro Cabezón y Lázaro Cárdenas, que actualmente pertenecen al municipio de Ahome. La cabecera del municipio sería la ciudad de Juan José Ríos. Política y administrativamente se dividiría en las sindicaturas

6 El impuesto predial rústico es una contribución que grava los terrenos destinados a la agricultura, acuicultura, ganadería, porcicultura y avicultura, conforme al valor de su producción anual comercializada. En el Decreto N.$^{\circ} 375$ publicado en el periódico Oficial N. ${ }^{\circ} 099$ del Gobierno Estatal el día 18 de agosto del año 2003 establece que los recursos generados por esta contribución se iban a aplicar exclusivamente en las zonas rurales de los municipios con la finalidad de atender los fuertes rezagos que padecen.

7 Guasave es el municipio y la cabecera municipal lleva el mismo nombre. No es el caso del vecino municipio de Ahome cuya cabecera se denomina Los Mochis. Guasave es un nombre indígena que significa entre milpas o en la labor, según se reporta en el portal web del H. Ayuntamiento de Guasave. 
de Juan José Ríos y Bachoco y las comisarías de Héroes Mexicanos y Bachoco II (Congreso del Estado de Sinaloa, 2014).

Los Diputados del Partido de Acción Nacional (PAN) presentaron un proyecto similar, diferenciándose en la división política y administrativa, dándole el estatus de sindicatura a Bachoco, Héroes Mexicanos y Agua de las Arenas y contemplaba la adhesión de comunidades del municipio de Sinaloa de Leyva. En resumen, los trámites de municipalización de Juan José Ríos han generado seis iniciativas o decretos y ocho reformas a la Constitución Política del Estado, la última de ellas el 28 de enero de 2014, sin embargo, para los promotores de la municipalización, los resultados han sido infructuosos hasta el día de hoy (Congreso del Estado de Sinaloa, 2014).

Con justa razón, la falta de atención y los rezagos acumulados han sido el caldo de cultivo de brotes de inconformidad que llegan al grado de convertirse en movimientos pro-municipalización, es decir, en intentos de independizarse del municipio para empezar a escribir una nueva historia municipal. No obstante, los proyectos no han tenido el apoyo del gobernador en turno, el fiel de la balanza en esta clase se asuntos, más aún en un país en la que el poder del ejecutivo sigue estando por encima de los demás órganos de gobierno . $^{2}$

\section{DISMINUCIÓN DE MUNICIPALIDADES (FUSIÓN): TENDENCIA MUNDIAL}

Alemania es uno de los países que ha impulsado una oleada de reformas territoriales dirigidas a crear mayores ciudades mediante la fusión e integración de pequeños municipios, reduciendo al mismo tiempo el número de los entes intermunicipales (Wollmann e Iglesias, 2011). De igual manera, en Francia, es decir, en el país de la intermunicipalidad por excelencia, la crítica a los entes intermunicipales está siendo cada vez más fuerte. La intermunicipalidad puede entenderse como una forma jurídica que permite la coordinación de actividades con presupuestos independientes en esencia y parcialmente compartidos (Ayup, 2007).

Sin embargo, algunas de las principales recomendaciones se orientan a simplificar y reducir la intermunicipalidad y abrir el sendero legal e institucional hacia el establecimiento de ciudades de mayor tamaño mediante la fusión e integración municipal (Wollmann e Iglesias, 2011). En ese sentido, Santiago (2013), al mencionar las etapas del proceso de fusión de los municipios, señala que la gestión compartida de municipios es un paso previo a su eventual fusión.

Por su parte, Barrios (2005, pág. 203) afirma que, en las fusiones de territorios municipales para mejorar los criterios de factibilidad técnica y financiera en la producción o provisión de bienes públicos locales, muchas veces se sacrifica la identidad histórica de los pequeños municipios en aras de circunscripciones mayores.

En Europa del Este, después de la caída del comunismo, con la finalidad de mejorar la democracia y el autogobierno local, se implementaron reformas que han implicado la fusión de municipios mediante el establecimiento de niveles regionales de gobierno, la descentralización de las funciones del nivel central al local, así como la institución de nuevas formas de participación ciudadana, sin embargo, la carencia de recursos y la autonomía financiera limitada no han coadyuvado a obtener mejores resultados en el fortalecimiento de los gobiernos locales (Colino, 2013).

En el 2007 Dinamarca redujo el número de municipios de 271 a 98 y el número de condados de 14 a 5 «regiones», esto en el marco de una búsqueda de economías de escala (Colino, 2013). De igual forma, un símil del segundo factor se ha presentado en España, Bélgica e Italia, donde las comunidades autónomas han asumido competencias de algunas provincias o condados.

Font y Galán (2012) también proponen como mejor solución la reducción del número de municipios por la vía de su fusión. La política de fusión de municipios debe partir de un estudio previo que demuestre los eventuales beneficios en términos de eficiencia. Es preciso cuantificar con precisión el ahorro calculado.

En ese mismo marco de ideas, Santiago (2013) señala que los gobiernos locales fusionados deben disponer de recursos suficientes para el cumplimiento de las competencias municipales y no suponer una disminución en la calidad de los servicios prestados.

8 Líneas atrás se mencionó la iniciativa propuesta por el Gobernador Renato Vega Alvarado (1992-1998) para crear el municipio de Eldorado. En realidad, fue un proyecto que nunca tuvo el respaldo político del gobierno de esa época, como lo demuestra el hecho de que presentó la iniciativa en la recta final de la LXII Legislatura, ya sin tiempo de ser dictaminada, por lo que se heredó ese espinoso asunto a la nueva administración de gobierno y, específicamente, a la nueva Legislatura. 
Los promotores de la fusión municipal toman en consideración la inoperatividad de los pequeños municipios al no garantizar la efectividad en la prestación de los servicios de su competencia (Santiago, 2013).

Para concluir, una de las críticas al proceso de fusión, la encontramos en Cadaval y Caramés (2015) quienes señalan que:

[...] en primer lugar, no encuentra una evidencia robusta de la influencia de la fusión sobre el gasto agregado municipal; ni sobre el aumento ni sobre la disminución. Además, tampoco hay evidencia de economías de escala en las pequeñas jurisdicciones o en aquellas con preferencias homogéneas. Por último, cuando se generan, se usan para elevar el nivel del servicio, no para reducir el gasto (pág. 76).

Estos autores concluyen, sobre el tema de fusión municipal, que a pesar de que se consigan economías de escala, los niveles de gasto pueden no reducirse porque el ahorro se dedica a otras líneas presupuestarias, sin embargo, afirman que «[...]podría generar una mejora en la calidad de los servicios, al incorporarse más experiencia o mejor formación en los trabajadores» (pág. 75).

Ultiman que, no todos los países han podido culminar con éxito procesos de fusión entre sus municipios, habiendo de atajar los problemas a través de fórmulas diferentes (Cadaval y Caramés, 2006).

Al respecto conviene señalar que, a pesar del entusiasmo inicial, la fusión de municipios presenta un fuerte rechazo social debido al costo político por la pérdida de representatividad y capacidad para defender sus intereses. Como prueba de lo anterior, en España esta estrategia no ha tenido el éxito esperado debido a la nula e xistencia de estudios que cuantifiquen el ahorro efectivo de recursos. La reducción del número de municipios sólo sería constitucionalmente justificable si garantizara una reducción notable del gasto público (Santiago, 2013).

Santiago (2013) continúa criticando la fusión municipal al afirmar que en esta se presenta una nula generación de economías de escala por parte de municipios pequeños. Aún en la fusión, el problema de dispersión poblacional no desaparece y la necesidad de prestar los servicios públicos seguirá existiendo. En lugar de proceder a la fusión, lo más conveniente sería revisar la distribución de competencias, entre cada nivel de gobierno.

Como antecedente de los resultados adversos de la fusión municipal, en Quebec, Canadá, al presentarse un proceso de défusion (escisión) en el fenómeno de fusiones forzosas del período 2000-2003, a partir de 2004 se presentó una contra tendencia al permitir la restructuración de las viejas municipalidades que habían sido obligadas a fusionarse. En cierta medida es como deshacer la fusión forzosa (Boto, 2007).

\section{ASOCIACIÓN DE MUNICIPIOS}

Mattar (2014), dentro de las nuevas tendencias de la descentralización, incorpora la asociatividad y autonomía, lo que merece destacarse porque probablemente serán elementos que en los próximos años estarán presentes en la discusión y en la práctica de la descentralización. Con políticas de asociatividad se agrupan territorios hacia la construcción de políticas públicas de manera mancomunada, no sólo en el ámbito nacional, sino también en el desarrollo de proyectos de cooperación transfronteriza.

Al hacer un comparativo entre fusión y asociación, Cadaval y Caramés (2015) afirman que la primera de estas, aunque fuese el remedio idóneo, encuentra numerosos obstáculos, principalmente de carácter sociológico. En ese sentido, recomiendan la asociación, con uno o varios fines u objetivos, inclinándose hacia la asociación municipal.

Arellano (2011) afirma que la tendencia a nivel internacional es que los gobiernos locales no sólo desarrollen la habilidad de administrar eficientemente sus recursos, sino que sean capaces de articular en torno a sí mismos acciones de otros agentes de la sociedad. La asociación de municipios se constituye en principal interlocutor entre los niveles central y local (Colino, 2013). Furlan, et al. (2014) resumen que de lo que se trata es lograr acuerdos y gestionar colectivamente el proceso asociativo, con competencias y recursos puestos en valor para hacer una economía de escala, en temas que son imprescindibles.

Existen experiencias de proyectos abordados por conjuntos de municipios que ilustran los beneficios de una estrategia de esta naturaleza, tales como en Argentina, que buscan disminuir los niveles de contaminación de los cursos de agua y espacios verdes; Norte Paceño Tropical en Bolivia; San Antonio Huista en Guatemala; en Nicaragua cinco municipios están dedicados al desarrollo territorial; y, en Michoacán, México, 4 municipios crearon el Centro de Tratamiento de Residuos Sólidos (CITIRS) El Marqués (Ziccardi, 2012). 
Los cinco proyectos forman parte del Proyecto Ideal del Programa URBAL III, programa de cooperación regional de la Comisión Europea con América Latina cuyo objetivo es incrementar el grado de cohesión social y territorial en el seno de las colectividades subnacionales y regionales de América Latina.

Sin embargo, Furlan et al. (2014) exponen que México, siendo un país altamente municipalizado, el tema de colaboración horizontal municipal es casi nulo, la razón es porque los gobernadores no quieren trabajar con actores locales fortalecidos. Según Arellano (2011), el nivel de asociacionismo municipal en México es incipiente, únicamente un tercio de los gobiernos locales mantienen redes de colaboración entre municipios o con el gobierno estatal.

A la par, Carrera (2005) complementa que la intermunicipalidad es de adopción muy reciente en México, por lo que no existe aún una definición comúnmente aceptada, sin embargo, la reforma al Artículo 115 Constitucional de 1983, sustenta esa figura al otorgarle al municipio la capacidad de coordinarse y asociarse entre ellos. Cadaval, citado por Carrera (2005), define la intermunicipalización como una fórmula de colaboración entre dos o más municipios -dotada de personalidad jurídica- para la realización de una o varias tareas.

Carrera (2005) apuntala dicho concepto al señalar que la intermunicipalización puede ser la base para que los gobiernos municipales se conviertan en actores políticos con mayor capacidad de decisión y negociación frente a los ámbitos superiores de gobierno, lo cual podría generar un nuevo modelo de relaciones intergubernamentales más equilibradas en México. Asevera que la asociación intermunicipal aparece como la mejor opción para lograr una solución eficaz y eficiente para que un gran número de municipios puedan satisfacer las demandas básicas de su población en materia de servicios públicos.

Así, se puede decir que la intermunicipalidad es un tipo de asociación voluntaria entre municipios, que se caracteriza por constituirse formalmente, es decir con reglas del juego explícitas; se establece con la intención de resolver problemas afines, en particular los relacionados con el suministro de servicios públicos, pero también con la intención de avanzar en la construcción de buenos gobiernos locales, aquellos que con sus acciones contribuyen a mejorar la calidad de vida del conjunto de la ciudadanía (Ziccardi, 2012).

Carrera (2005) atribuye la asociación de municipios a intereses propios de los involucrados o en su defecto podría presentarse por recomendación de los niveles de gobierno superiores, incluso, por agencias internacionales, afirma que la asociación intermunicipal podría ser la mejor opción para lograr una solución eficaz y eficiente para que un gran número de municipios puedan satisfacer las demandas básicas de su población en materia de servicios públicos. Colino (2013) resume que este tipo de asociación conviene a las autoridades centrales debido a que se puede confiar que los compromisos pactados pueden ser asumidos por un número significativo de autoridades locales y da cabida a las municipalidades pequeñas a participar en el proceso de adopción de decisiones e influir así de algún modo en el resultado final.

Sin embargo, Wollmann e Iglesias (2011) refutan lo anterior señalando que la inter-municipalidad también presenta disfunciones, entre otras que: buen número de pequeños municipios están sub representados en los órganos intermunicipales, en muchos de ellos ni siquiera hay candidatos para las elecciones locales por lo que bien podría afirmarse que la democracia local no encuentra instrumentos para hacerla operativa; y, los entes intermunicipales encuentran enormes dificultades para fomentar y facilitar la cooperación entre sus municipios, generando numerosos problemas de coordinación, incrementándose así los costos de transacción (Colino, 2013).

\section{RESULTADOS}

Una de las formas más eficaces de medir la atención del gobierno municipal hacia sus comunidades es mediante la atención que les ofrece en la prestación de los servicios públicos. El grado de satisfacción de los ciudadanos se puede medir en relación con la calidad y efectividad de los servicios públicos que sus autoridades les ofrecen y a los que tienen derecho como fruto de las contribuciones que pagan a los distintos órdenes de gobierno.

Desde la óptica de los ciudadanos los servicios públicos más deficientes en cuanto a cobertura y calidad fueron: agua potable, drenaje sanitario, alumbrado público, pavimentación y recolección de basura, en ese orden. De la totalidad de los encuestados, el $78.33 \%$ señaló que el servicio de agua potable mostraba deficiencia en su prestación, de estos, el $56.38 \%$ lo calificó como el más problemático en la sindicatura. El servicio de drenaje y alcantarillado, el $44.44 \%$ que lo mencionó, lo ubicaron como el segundo servicio público con más problemas y en tercer lugar el de alumbrado público con el $38 \%$ de 
opiniones negativas en cuanto su cobertura y calidad. En relación al servicio de seguridad pública, solo el $6.7 \%$ lo catalogó como el más deficiente, mientras que el $10.80 \%$ lo ubicó en el segundo peldaño de servicios con problemática.

Al indagar sobre las razones que daban origen a la deficiencia en los servicios públicos ya mencionados, más del $50 \%$ de la muestra le atribuye la responsabilidad a la autoridad municipal, al señalar que hacen mal manejo de los recursos y han mostrado desinterés en mejorar la prestación de los servicios públicos; en ese mismo enfoque, casi el $19 \%$ señaló que la problemática se origina por la falta de recursos para ser atendidos y un porcentaje cercano al $12 \%$ le atribuye a los costos de mantenimiento que conllevan la prestación de los mismos.

\section{FiguRA 2. RAZONES QUE ORIGINAN LA PROBLEMÁtICA EN LOS SERVICIOS PÚBLICOS}

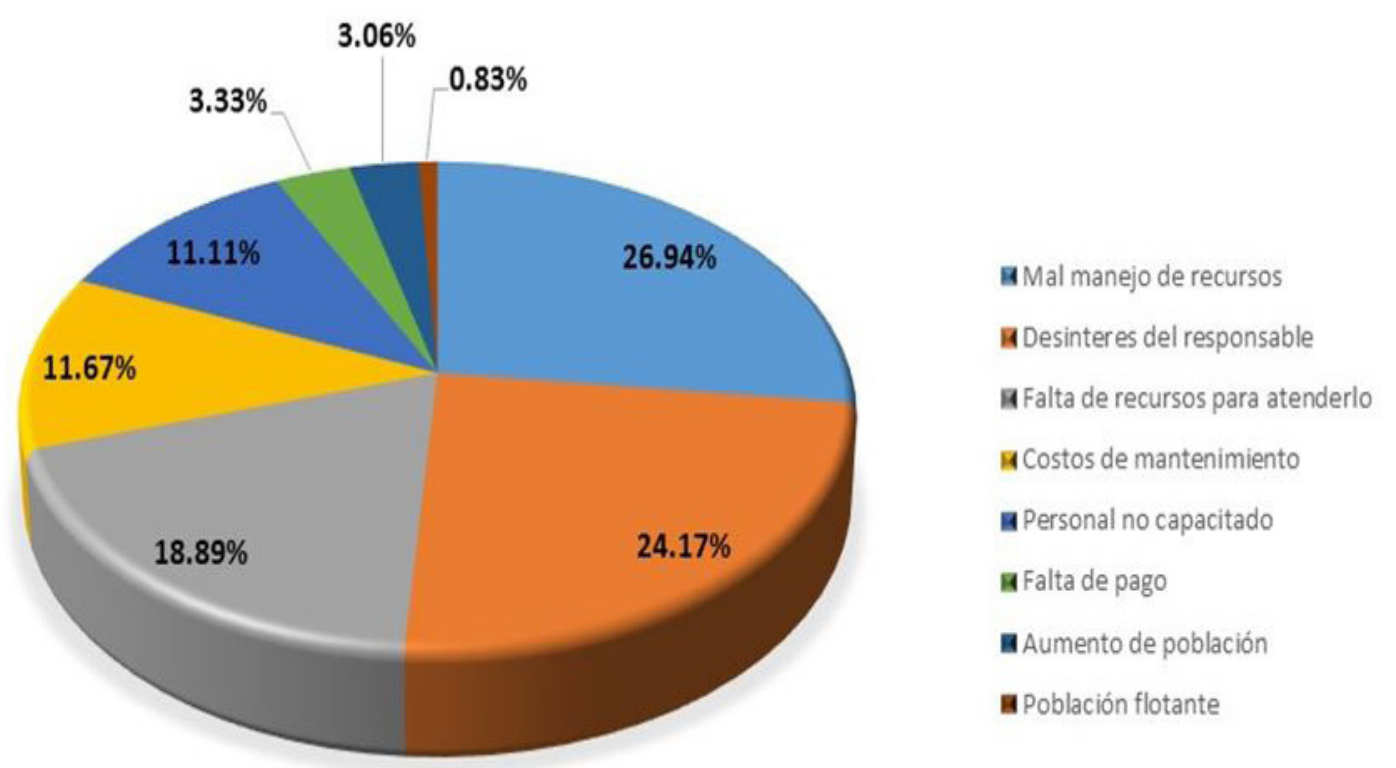

Fuente: Elaboración propia. @ Portillo M., Raúl; Rodríguez V., Julio César y García U., Daniel.

Al adentrarnos a la variable financiera, como complemento al mal manejo de los recursos y carencia de los mismos, el $79.2 \%$ afirmó que no había una distribución equitativa de los ingresos fiscales entre las autoridades auxiliares y el $80.8 \%$ le adicionó que tampoco se distribuían cumpliendo con el principio de justicia distributiva. Al cruzar ambos principios (justicia y equidad) el $72.5 \%$ afirmó que no se cumplía con ninguno de estos, solo el 1.7 aseveró que sí y el $11.7 \%$ se mantuvo al margen al responder que desconocían.

Una vez identificada la inequidad distributiva de los recursos, y proponer alternativas para mejorar la situación, dentro del universo de los que afirmaron que no hay equidad distributiva, el $81.1 \%$ está de acuerdo que el $\mathrm{H}$. Ayuntamiento implemente fórmulas distributivas por sindicatura, independientemente de cuál sea su fuente de origen, la cual deberá de retomar los factores de número de habitantes, extensión territorial, eficiencia recaudatoria, pobreza y número de localidades, en ese orden, por sindicatura. El $36.7 \%$ señaló que el factor «población» debería de considerarse como el primer factor para estructurar la formula y el $35.8 \%$ el de «extensión territorial» como segundo elemento.

A pesar de señalar que los recursos no se manejan con transparencia en la prestación de los servicios públicos, los encuestados le dieron más importancia al factor «eficacia recaudatoria» de la sindicatura que al de «pobreza». El $23.3 \%$ y $6.7 \%$, respectivamente, marcaron que debería ser el tercer elemento de la fórmula.

La falta de equidad distributiva de recursos hacia el medio rural alienta el deseo de incrementar el grado de autonomía de las autoridades auxiliares del municipio de Guasave, pues el $72.6 \%$ de los que señalaron inequidad considera que municipalizar sindicaturas propiciaría el fortalecimiento de medio rural del municipio. En ese mismo sentido, el 76.3 \% también apoya la municipalización de la sindicatura de Juan José Ríos. 


\section{Figura 3. Resultados de La municipalización de la Sindicatura de JuAN José Ríos}

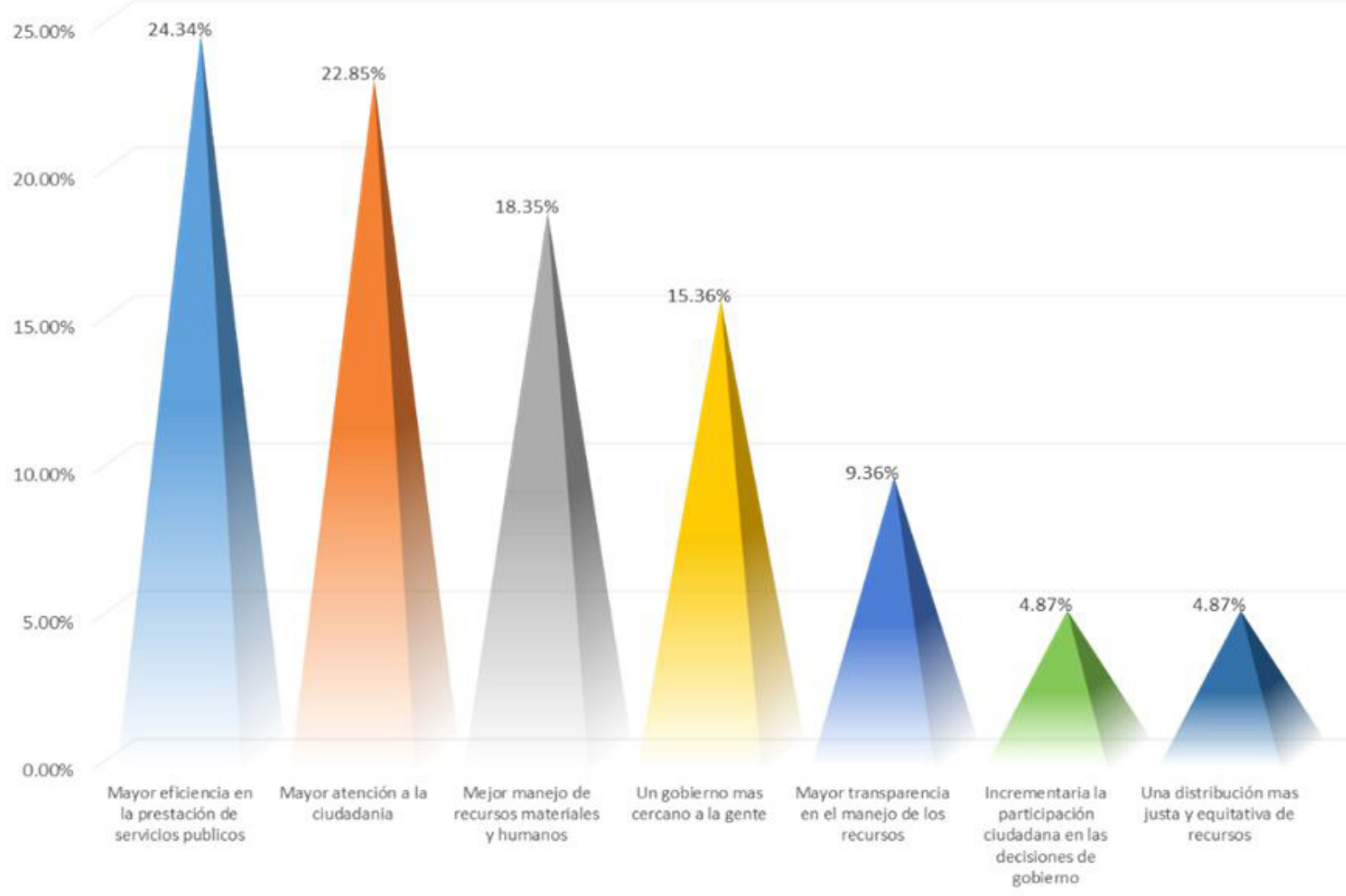

Fuente: Elaboración propia. @ Portillo M., Raúl; Rodríguez V., Julio César y García U., Daniel.

Sin embargo, al tratar de identificar la percepción acerca de los eventuales resultados que tendría el proceso de municipalización, el $24.34 \%$ afirmó que se lograría una mayor eficiencia en la prestación de servicios públicos, el $22.85 \%$ se daría mayor atención a la ciudadanía y el $18.35 \%$ mejoraría el manejo de recursos materiales y humanos.

Se ha reiterado la disparidad en el gasto público que normalmente beneficia a las cabeceras municipales en detrimento del resto de las comunidades del municipio. ¿Cambiaría ese esquema de gobierno en un eventual nuevo municipio? Las personas piensan que no, creen que se reproduciría la situación actual. Solo el $4.87 \%$ de los encuestados señaló que se presentaría una distribución más justa y equitativa de los mismos. De igual forma, otro de los beneficios que se generarían por la municipalización de sindicaturas que no fue apoyado es incrementar la participación ciudadana en las decisiones de gobierno. Apenas el $4.87 \%$ seleccionó esa alternativa.

De acuerdo a los resultados, la primera conclusión de esta investigación es que la municipalización de sindicaturas no es el camino más apropiado para avanzar hacia un desarrollo más homogéneo y equilibrado de las poblaciones que existen en los municipios. Parece más acertado diseñar estrategias y modalidades que den fortaleza y autonomía a las autoridades auxiliares, fórmulas de autogobierno que impulsen la organización y aprovechen de manera más óptima la energía social y los recursos disponibles.

Hoy, la posibilidad de municipalización apunta hacia la sindicatura de Juan José Ríos, una de las más grandes en cuanto al número de habitantes y aportación al PIB del municipio de Guasave; sin descartar que, en los años por venir, otras sindicaturas de este municipio como Benito Juárez y Adolfo Ruiz Cortines podrían sumarse a ese proceso de separación por presentar características similares. Sin embargo, habría que preguntarse si la fragmentación de un municipio es la mejor alternativa para optimizar el rendimiento del gasto público.

Una más de las estrategias rechazadas por la mayoría de los encuestados lo fue la fusión de las sindicaturas, ya sea del mismo municipio o con otros colindantes. Al cuestionar si estaría de acuerdo que fusionarse (unirse) con una o más sindicaturas, generaría una mejor atención en materia de servicios públicos, el $50 \%$ 
señaló no estar de acuerdo con esta modalidad, el $40 \%$ contestó favorablemente a esta interrogante y un $10 \%$ no sabía si era conveniente.

El análisis de los datos obtenidos no se limitó a las respuestas de los encuestados, sino que fue necesario hacer un cruce de información y medir realmente la mejor estrategia para el fortalecimiento del medio rural del municipio de Guasave. Retomando la decisión de implementar fórmulas distributivas y hacer el comparativo con las respuestas de la interrogante relacionada a la fusión de sindicaturas, los que negaron que la fusión generaría el fortalecimiento integral, el $86.70 \%$ señaló como alternativa favorable la implementación de fórmulas distributivas de los recursos que se canalizan al medio rural, independientemente de su fuente de origen. Es decir, se inclinaron a sembrar el embrión de un sistema municipal de coordinación fiscal, que implique derechos y responsabilidades tributarias al interior del municipio mismo. Solamente el $13.3 \%$ afirmó que no es conveniente ninguna de las dos estrategias.

Sin embargo, al comparar entre fusión y municipalización de sindicaturas, dentro de los que no aceptaron la fusión, el $76.7 \%$ apuntó estar de acuerdo en la municipalización. Obsérvese, entre estas tres estrategias, los que no están de acuerdo en la fusión, prefieren la distribución justa y equitativa de recursos antes que la municipalización. En ese mismo sentido, ante la pregunta expresa: ¿De no lograr transitar hacia la municipalización la sindicatura de Juan José Ríos por motivos diversos, estaría usted de acuerdo con la fusión, como estrategia complementaria? el $56.7 \%$ expresó no avalar esa estrategia novedosa de fortalecimiento y un $15 \%$ adicional señaló que desconocía el tema. Solo el $28.3 \%$ expuso que, si no se municipalizaba la sindicatura, apoyaría la fusión de la misma.

La asociación de sindicaturas, como medida de apoyo para el mejoramiento de los servicios públicos y, por ende, del fortalecimiento del medio rural del municipio de Guasave, es una estrategia de mejor aceptación que las estrategias anteriormente señaladas. El $55.8 \%$ se inclinó a apoyarla, un $35.8 \%$ se opuso y el $8.3 \%$ no mostró postura alguna. A pregunta directa: ¿De no lograr transitar hacia la municipalización de la sindicatura de Juan José Ríos por motivos diversos, estaría usted de acuerdo con una asociación de sindicaturas? el $47.5 \%$ dijo apoyar esta medida y el $38.3 \%$, señaló lo contrario, dando la pauta para resumir, que si no se transitaba hacia la municipalización tampoco aceptaría la asociación de la misma.

En relación al cruce de información entre la estrategia de asociación y la implementación de fórmulas distributivas de los recursos, el $82.1 \%$ que está de acuerdo con la asociación también apoya la implementación de un sistema municipal de coordinación municipal.

FIgURA 4. ¿CUÁL SERÍA LA ESTRATEgIA QUE GENERARÍA UN MAYOR DESARROLLO Y CRECIMIENTO DE LA Sindicatura de JuAN José Ríos?

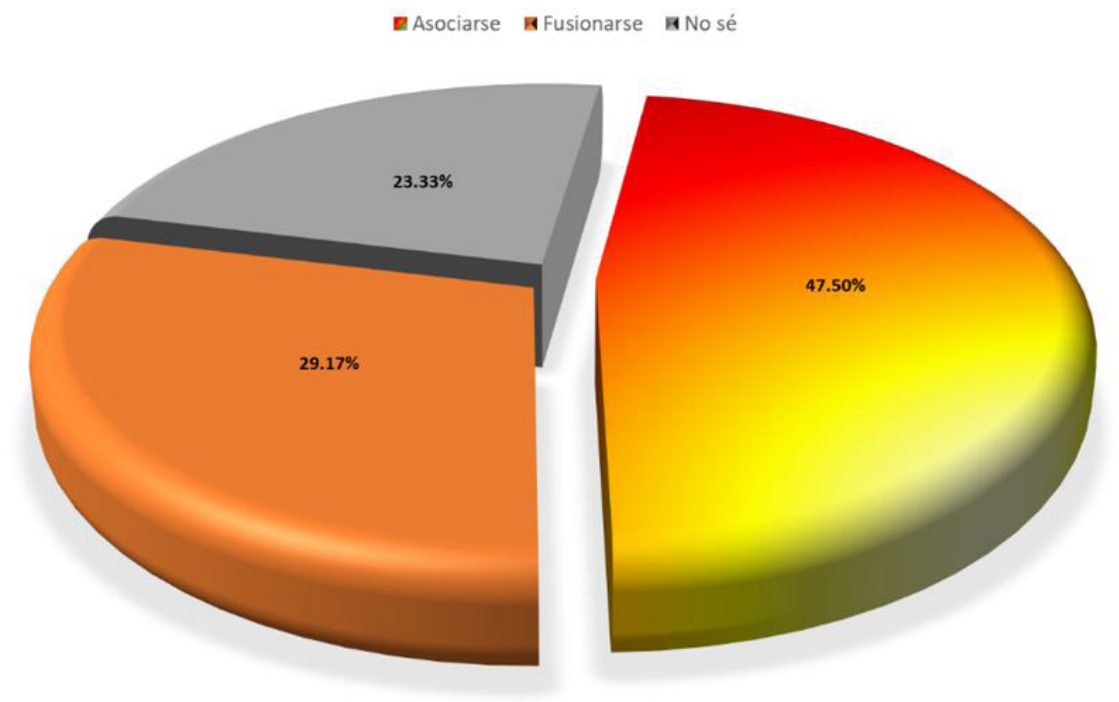

Fuente: Elaboración propia. @ Portillo M., Raúl; Rodríguez V., Julio César y García U., Daniel.

Con la finalidad de erradicar la confusión de las preferencias que podrían generarse entre la fusión y la asociación de sindicaturas, al cuestionar dicha situación, el $47.5 \%$ se inclinó a la asociación y solo el $29.17 \%$ a la fusión (véase Figura 4). 
Para culminar con el análisis de la situación al interior de las sindicaturas, el consenso es unánime, los ayuntamientos privilegian a las cabeceras municipales en detrimento de la calidad de vida de las demás comunidades del municipio. La insuficiencia de los recursos municipales para atender las complejas demandas de su entorno y la crítica constante de la calidad de los servicios y obra pública son las principales limitantes a su crecimiento y fortalecimiento.

En ese sentido, según los encuestados, cinco son los principales problemas que han limitado el crecimiento de su sindicatura. El primero de ellos es la centralización de recursos en la cabecera municipal que todos los días se manifiesta a través de decisiones verticales en el ejercicio de gobierno, a pesar de que un ciudadano del medio rural tiene el mismo derecho de que vive en zonas urbanas de gozar de mejores índices de bienestar. El $36.41 \%$ señaló que este es el principal problema del municipio hacia el medio rural.

Los ciudadanos consultados ven la falta de recursos económicos de las sindicaturas como el segundo factor que ha perjudicado su desarrollo. El $24.62 \%$ de la muestra lo mencionó así. El tercer lugar lo ocupa la ineficiente coordinación entre sindicaturas y el gobierno municipal, el $17.44 \%$ de la muestra expresó esa inquietud.

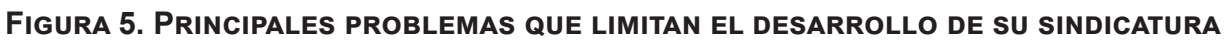

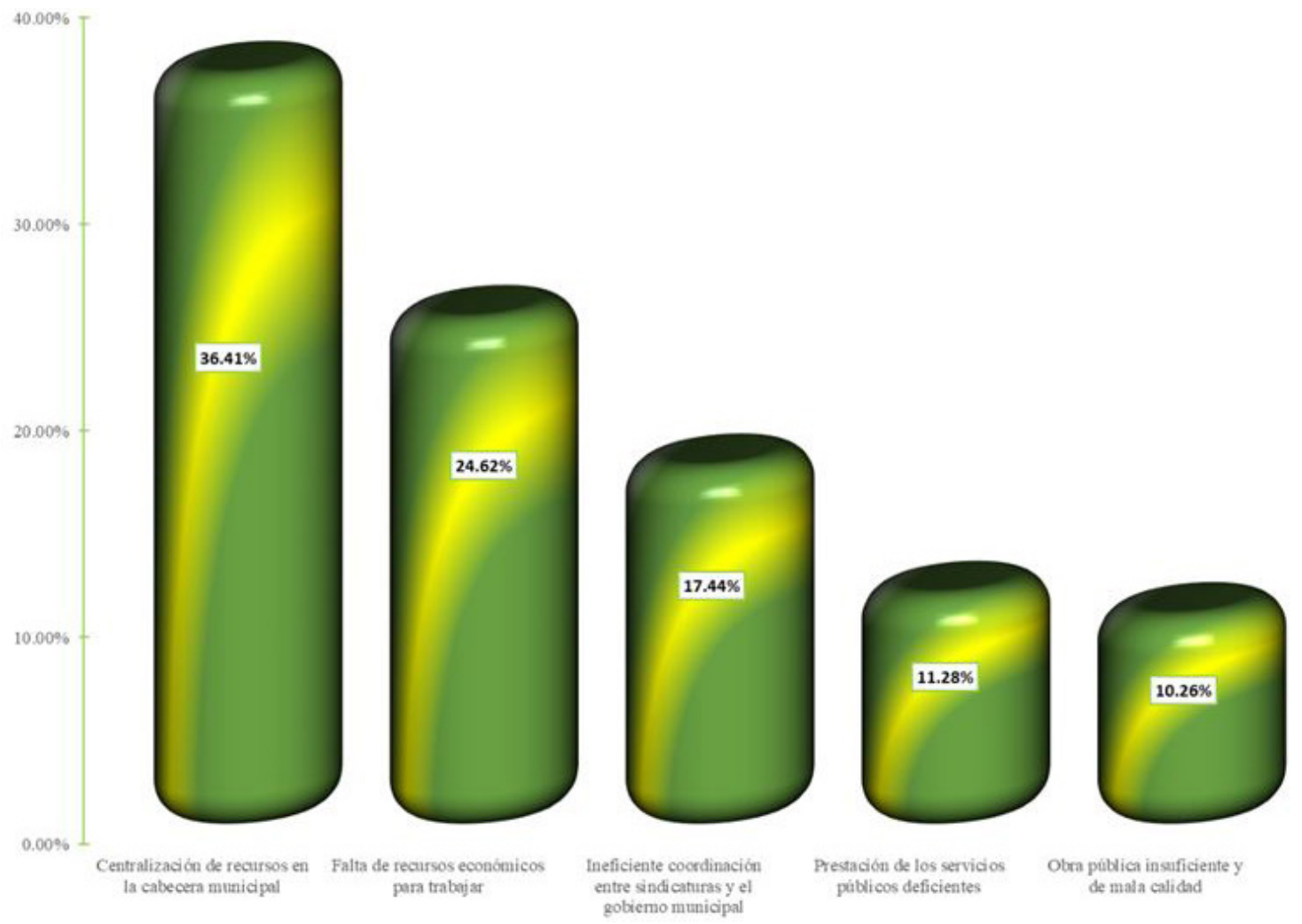

Fuente: Elaboración propia. @ Portillo M., Raúl; Rodríguez V., Julio César y García U., Daniel.

A pesar de que anteriormente se había mencionado que el principal problema es la ineficiente prestación de servicios públicos, para los ciudadanos consultados la centralización en obras y programas en la cabecera municipal, la falta de recursos de las sindicaturas y la ineficiente coordinación, son las situaciones de mayor impacto en su desarrollo. Visto de otra manera, para los ciudadanos queda claro que la deficiencia en la prestación de los servicios públicos y la falta de obras de infraestructura, son una consecuencia de los problemas ya relatados. Solo el $11.28 \%$ dio prioridad a la calidad de los servicios públicos y el $10.26 \%$ a la obra pública, como problemática en su desarrollo.

Si se va a postergar el fortalecimiento de las sindicaturas, al menos los ayuntamientos deben enseñarse a distribuir más igualitariamente los recursos, es inaplazable una profunda reforma municipal dirigida al fortalecimiento de sus autoridades auxiliares. Más que fragmentar al estado en múltiples municipios, lo que se requiere es generar mecanismos y estructuras adecuados a las exigencias y necesidades de sus comunidades, que aspiran con todo derecho a un crecimiento sostenido de sus niveles de vida. 


\section{CONCLUSIONES}

Sobre la base de la generalidad de la problemática municipal que existe a nivel nacional, se considera que los tiempos actuales no son los más propicios para crear nuevas municipalidades, más aún si alumbran en medio de la carencia de recursos y limitada capacidad de prestación de servicios públicos. La conversión de autoridades auxiliares en municipios no parecer ser la solución más adecuada a los problemas que sufren en cada comunidad.

El centralismo dentro de los municipios se traduce en resistencias a reconocer el legítimo derecho que tienen las sindicaturas de gozar de más atribuciones para atender la prestación de los servicios públicos que reclaman sus habitantes. El problema más profundo es que se está desaprovechando la energía social y la organización comunitaria, que bien encauzadas podrían multiplicar el efecto de los recursos públicos.

En conclusión, la problemática en particular hacia el interior del tercer nivel de gobierno, se resume en la exigencia de una atención oportuna por parte del gobierno municipal a sindicaturas y comisarías y por ende a comunidades del medio rural, mediante el incremento de recursos materiales, humanos y financieros para hacerle frente a las demandas de sus habitantes, mediante la efectiva prestación de servicios públicos y un incremento en el inventario de infraestructura en obra pública, demandas generalizadas de los habitantes de la gran mayoría de los municipios en México.

No puede perderse de vista que la creación de un municipio implica destinar fuertes cantidades de recursos para crear un nuevo aparato público y sostener a la burocracia y el gasto corriente. Crear nuevos municipios no resuelve de fondo el problema, en todo caso lo que se consigue es que surja en esos nuevos entes la misma desigualdad y desequilibrio que se observa en los ya constituidos, es decir, se corre el riesgo de privilegiar a las cabeceras municipales y de marginar en mayor o menor medida al resto del territorio de un eventual nuevo municipio.

La ruta de la municipalización no es un camino fácil ni mucho menos un trámite rápido. No olvidemos que un proceso de independencia, de autonomía municipal, es una lucha donde hay vencedores y vencidos. Por eso, el mejor camino siempre será aquel que brinde soluciones justas y equitativas, donde predomine el buen juicio y prevalezcan los legítimos intereses de quienes aspiran a mejorar su calidad de vida. Vale la pena hacer un juicio sereno y objetivo de todo lo que implica la creación de nuevas municipalidades para dar respuesta objetiva a la interrogante: ¿será la creación del municipio número 19 del estado de Sinaloa el camino a seguir?

\section{REFERENCIAS BIBLIOGRÁFICAS}

ARELLANO GAULT, D.; CABRERO MENDOZA, E.; MONTIEL CUATLAYOL, M. J.; AGUILAR MÁRQUEZ, I. (2011): "Gobierno y administración pública municipal: Un panorama de fragilidad institucionalizada", en CABRERO MENDOZA, E., y ARELLANO GAULT, D. (coords.), Los gobiernos municipales a debate: un análisis de la institución municipal a través de la Encuesta INEGI 2009, págs. 29-116. México, D. F.: Centro de Investigación y Docencia Económicas. En línea: http://hdl.handle.net/10089/16462.

ARELLANO RÍOS, A. (2011): "El gobierno al interior del municipio mexicano: reflexiones en torno a su diseño institucional”, en Región y Sociedad, vol. 23, núm. XXIII, págs. 59-90. En línea: http://www.redalyc.org/articulo. oa?id=10221416003. DOI: https://doi.org/10.22198/rys.2011.52.a182.

ARZE DEL GRANADO, F. J.; MARTÍNEZ VÁZQUEZ, J. (2004): "Descentralización en América Latina desde una perspectiva de países pequeños: Bolivia, El Salvador, Ecuador y Nicaragua”, en Gestión y Política Pública, segundo semestre, vol. XIII, núm. 3, págs. 619-661.

ASE (2016): Auditoría Superior del Estado de Sinaloa. Informes de cuentas públicas. En línea [consultado el 17 de septiembre de 2018]: http://www.ase-sinaloa.gob.mx/index.php/municipios.

AYUP GONZÁLEZ, Y. (2007): “Imagen intermunicipal. Planeación intermunicipal y un cambio en la comunidad”, en MONTEMAYOR MARIN, M. C.; BIJARRO HERNANDEZ, F.; ESTRADA BELLMANN, P. C. (coords.): Políticas y gestión pública para el estudio municipal: experiencias exitosas, el sector público, págs. 68-87. México: Universidad Autónoma de Tamaulipas.

BARRIOS SUVELZA, F. J. (2005): "Efectos de espacio sobre costos de provisión local. Un modelo de ecualización por bloques para los municipios bolivianos”, en Revista de Economía Institucional, vol. 7, núm. 13, págs. $193-225$.

BOTO ÁlVAREZ, A. (2007): "El proceso de fusión y segregación municipal en Quebec", en Revista de Estudios de la Administración Local y Autonómica (REALA), núm. 305, págs. 247-276. En línea, DOI: https://doi.org/10.24965/ reala.vi305.9363. 
BRAVO, M. A. (2017): Este es el municipio más joven de México. En línea [consultado el 14 de septiembre de 2018]: https://www.publimetro.com.mx/mx/noticias/2017/12/19/estos-los-dos-municipios-jovenes-mexico.html.

CABRERO MENDOZA, E.; GARCÍA, C. G. (2010): "La agenda de políticas públicas en ciudades mexicanas durante el siglo XX: ¿cien años de soledad municipal?”, en Estudios Demográficos y Urbanos, vol. 25, núm. 1, $133-173$. En línea: $h t t p: / / w w w . r e d a l y c . o r g / a r t i c u l o . o a ? i d=31221540005$. DOI: $h$ ttps://doi.org/10.24201/edu.v25i1.1370.

CABRERO MENDOZA, E.; DÍAS ALDRET, A. (2012): "La acción local en periferias urbanas marginadas de México", en Gestión y Política Pública, vol. XXI, núm. volumen temático 2012, págs. 83-129.

CADAVAL, M.; CARAMÉS, L. (2015): "El redimensionamiento de las jurisdicciones locales", en Urban Public Economics Review, núm. 21, págs. 64-83. En línea: https://www.redalyc.org/articulo.oa?id=50443064002.

CADAVAL, M.; CARAMÉS, L. (2006): “Una aproximación a los modelos de intermunicipalidad”, en Urban Public Economics Review, núm. 6, págs. 33-67. En línea: https://www.redalyc.org/articulo.oa?id=50400602.

CADENA INOSTROZA, C.; FRACO MAASS, S.; CAMPOS ALANÍS, H. (2007): "Territorialidad y política: El caso de la división del municipio de San Felipe del Progreso, Edomex”, en Gestión y Política Pública, vol. XVI, núm. 2, págs. 421-464.

CARRERA HERNÁNDEZ, A. P. (2005): "La intermunicipalización en México: una estrategia para el desarrollo de relaciones intergubernamentales más equilibradas", en X Congreso Internacional del CLAD sobre la Reforma del Estado y de la Administración Pública. Santiago, Chile, 18-21 Oct. 2005. En línea: http://cdim.esap.edu.co/ BancoMedios/Documentos\%20PDF/la\%20intermunicipalizaci\%C3\%B3n\%20en\%20m\%C3\%A9xico.pdf.

COLINO, C. (2013): "Los gobiernos y las administraciones locales" en PARRADO, S.; COLINO, C.; OLMEDA, J. A. (coords.), en Gobiernos y administraciones públicas en perspectiva comparada. Valencia: Tirant lo Blanch.

CONGRESO DEL ESTADO DE SINALOA (2016): Ley de Gobierno Municipal. Sinaloa, México. Última reforma publicada en el Periódico Oficial, núm. 80 del 1 de Julio de 2016.

CONGRESO DEL ESTADO DE SINALOA (2014): H. Congreso del Estado de Sinaloa. Unidad de Acceso a la Información Pública del Poder Legislativo. CEIPES. Folio INFOMEX: 00494914, Solicitada el 11 de Octubre del 2014 13:45 hrs.

CONGRESO DEL ESTADO DE SONORA (2015): Constitución Política del Estado Libre y Soberano de Sonora. Última reforma 16 de julio de 2015. En línea [consultado el 17 de enero de 2016]: http://www.atil.gob.mx/leyes/ CONSTITUCION\%2OPOLITICA\%20DEL\%20ESTADO\%20DE\%20SONORA.pdf.

CONGRESO DEL ESTADO DE TLAXCALA (2015). H. Congreso del Estado de Tlaxcala. Recuperado el 18 de enero de 2016 de Constitución Política del Estado Libre y soberano de Tlaxcala. Última reforma publicada en el periódico oficial: 30 de diciembre de 2015. En línea: http://www.tsjtlaxcala.gob.mx/transparencia/Fracciones_a63/I/ leyes/20190620_constitucionpolitica.pdf.

CONGRESO DE LA UNIÓN (2015): Cámara de Diputados del H. Congreso de la Unión. Recuperado el 22 de Junio de 2015, de Constitución Política de los Estados Unidos Mexicanos. En línea: http://www.diputados.gob.mx/ LeyesBiblio/pdf/1_060320.pdf.

DÍAZ, F. M. (2002): “Federalismo fiscal y asignación de competencias: una perspectiva teórica”, en Economía, Sociedad y Territorio, vol. III, núm. 11, enero-junio, págs. 387-407. México: El Colegio Mexiquense, A. C. En línea, DOI: $h$ ttps://doi.org/10.22136/est002002345.

EGUINO, H., PORTO, A.; PINEDA MANNHEIM, C. R.; GARRIGA, M.; ROSALES, W. (2010): Estudio de las características estructurales del sector municipal en América Latina. Banco Interamericano de Desarrollo. En línea [consultado el 7 de enero de 2016]: https://publications.iadb.org/handle/11319/4483.

FAGUET, J. P. (2004): "Does decentralization increase government responsiveness to local needs? Evidence from Bolivia", en Journal of Public Economics, vol. 88, núm. 3-4, págs. 867-893. En línea, DOI: https://doi.org/10.1016/ S0047-2727(02)00185-8.

FONT I LLOVET, T.; GALÁN GARCÍA, A. (2012): "Gobierno local y reorganización territorial: ¿la reforma vendrá de Europa?”, en Anuario del Gobierno Local, núm. 1, págs. 11-39. En línea: http://repositorio.gobiernolocal.es/xmlui/ handle/10873/1247.

FURLAN, J. L.; MOLINA, C. H.; PERDIGÓ I SOLÁ, J., MELLA, L. (2014): "Los municipios como estructuras básicas del estado. La mancomunidad (asociativismo) de servicios y las estructuras intermedias de gobierno, desafíos de transparencia y participación en el nivel local" en FERNÁNDEZ DE LOSADA, A.; SERRANO MADRID, C. (coords.): Descentralización, transparencia y seguridad jurídica en América Latina y Europa, págs. 133-152. Madrid: INAP.

GARCÍA, URIQUIDEZ. D. (2009): "Municipalización o Fortalecimiento de las Sindicaturas el caso de Juan José Ríos”, en SOTELO SANCHEZ, H.; IZAGUIRRE DÍAZ DE LEÓN, F.; DEMIRDJIAN Y PERCHEMLIAN, M. T. (coords.): Estrategias para el Desarrollo Organizacional y Regional, págs. 205-253. México: Universidad de Occidente. ISBN: 978-607-7796-01-5.

GOBIERNO DEL ESTADO DE SINALOA (2017): Plan Estatal de Desarrollo 2017-2021.

HERNÁNDEZ, S. R.; FERNÁNDEZ, C.; BAPTISTA, L. P. (2006): Metodología de la Investigación. 850 págs. México: McGraw Hill Interamericana Editores, S. A. de C. V. 4. ${ }^{\text {a }}$ ed.

INEGI (2010): Censo de Población y Vivienda 2010. Principales resultados por localidad (ITER). En línea [consultado el 6 de enero de 2016]: https://www.inegi.org.mx/programas/ccpv/2010/?ps=herramientas. 
INEGI (2015): División Territorial. Cuéntame de México. En línea [consultado el 4 de noviembre de 2018]: http:// cuentame.inegi.org.mx/territorio/division/default.aspx?tema=T.

INEGI (2017): Finanzas públicas estatales y municipales. Descripciones de los proyectos de consulta interactiva de datos. En línea [consultado el 14 de septiembre de 2018]: http://www.beta.inegi.org.mx/contenidos/proyectos/ registros/economicas/finanzas/doc/cobertura_1989_2017_PRE1_completo.pdf.

LÓPEZ PANIAGUA, R.; AYALA ORTIZ, D. A.; ARELLANES CANCINO, Y. (2017): "Gobernabilidad democrática y desarrollo local sustentable", en Economía y Sociedad, vol. 21, núm. 36, págs. 61-75.

LUGO, F. A. (2010): Factores que inciden en la toma de decisiones para la creación de nuevos municipios en México. Tesis de Doctorado Publicada. Santo Tomás, México, D. F.: Instituto Politécnico Nacional, Escuela Superior de Comercio y Administración. En línea: https://tesis.ipn.mx/bitstream/handle/123456789/7246/63. pdf?sequence=1\&isAllowed=y.

MANDUJANO RAMOS, N. (2011): "Federalismo y descentralización fiscal en México", en Dimensión económica, enero-abril 2011, vol. 2, núm. 5. En línea [consultado el 22 de octubre de 2012]: http://rde.iiec.unam.mx/revistas/5/ articulos/1/11.php.

MATTAR, J. (2014): "Principios básicos para la descentralización del estado: subsidiariedad, autonomía local, seguridad jurídica” en FERNÁNDEZ DE LOSADA, A.; SERRANO MADRID, C. (coords.): Descentralización, transparencia y seguridad jurídica en América Latina y Europa, págs. 51-83. Madrid: INAP.

MERINO, M. (1993): “Los municipios de México: El eslabón de la cadena”, en América Latina Hoy, vol. 6, págs. $33-38$. En línea: $h$ ttp://www.redalyc.org/articulo.oa?id=30800605.

MERINO, M. (2013): "La captura de los puestos públicos”, en Revista Mexicana de Ciencias Políticas y Sociales, vol. 58, núm. 219, págs. 135-156. En línea, DOI: https://doi.org/10.1016/S0185-1918(13)72306-7.

OATES, W. E. (2004): "An essay on fiscal federalism", en BAIMBRIDGE, M. \& WHYMAN, P.: Fiscal Federalism and European Economic Integration. London: Routledge. DOI: https://doi.org/10.4324/9780203987254.

ORTIZ, M. A. (2012): "Derecho municipal”, en CINCO, J.; INZUNZA, E.; VALADÉS, D. (coords.): Introducción a las Instituciones Jurídicas de Sinaloa. México D. F.: El Colegio de Sinaloa. ISBN: 978-607-7904-06-9.

PÉREZ ROMAN, B. I. (2012): Historia desde la fundación de la ciudad de Juan José Ríos, Sinaloa. En línea [consultado el 8 de enero de 2016]: http://dialogoconrealidadliteraria.blogspot.mx/2012/01/historia-desde-lafundacion-de-la.htm.

PORTILLO MOLINA, R.; RODRÍGUEZ VALDEZ, J. C.; GONZÁLEZ FRANCO, R. A.; VÉLEZ VÁQUEZ, M. G. (2015): "Discrecionalidad del gasto en los gobiernos locales de sinaloa: ¿fortaleza o debilidad?", en Revista científica: Teorías, enfoques y aplicaciones en las ciencias sociales, año 8, núm. 17, págs. 53-66.

PRECIADO CORONADO, J. (2009): "Creación de nuevos municipios en México. Procesos y perspectivas", en Frontera norte, vol. 21, núm. 42, págs. 205-209. En línea [consultado el 14 de septiembre de 2018]: http://www. scielo.org. $\mathrm{mx} /$ scielo.php?script=sci_arttext\&pid=S0187-73722009000200009\&lng=es\&tlng=es.

ROBLES, G. (2003): Diccionario de términos municipales. Sinaloa (México): Universidad de Occidente. 238 págs.

ROMO DE VIVAR MERCADILLO, M. R.; CHAUCA MALÁSQUEZ, P. M. (2007): "Reflexiones en torno al Federalismo Hacendario Mexicano", en Ciencia Nicolaita, núm. 47, págs. 19-32.

SALKIND, N. J. (1999): Métodos de Investigación. (ESCALONA, L. R. (trad.). 400 págs. México: Prentice Hall. 3. ${ }^{a}$ ed. ISBN: 970-17-0234-4.

SANTIAGO IGLESIAS, D. (2013): "El debate sobre el redimensionamiento del mapa municipal español”, en luris Tantum, núm. 24. En línea: https://2019.vlex.com/\#/vid/525548114.

SIERRA BRAVO, R. (1988): Técnicas de investigación Social. Teoría y Ejercicios. Madrid: Paraninfo.

SOUR, L. (2013): “The flypaper effect in Mexican Local Governments", en Estudios Económicos, vol. 28, núm. 1, págs. 165-186. En línea: $h t t p: / / w w w . r e d a l y c . o r g / a r t i c u l o . o a ? i d=59727431005$.

TANZI, V. (2008): "The future of fiscal federalism”, en European Journal of Political Economy, vol. 24, núm 3, págs. 705-712.

Ubicación municipio de Juan José Ríos (2013): En línea: https://juanjoseriosmunicipio.wordpress.com/2013/04/01/ ubicacion-municipio-juan-jose-rios/.

WOLLMANN, H.; IGLESIAS, A. (2011): "Transformación y cambio del gobierno local en Europa: un estudio comparativo", en Revista Castellano-Manchega de Ciencias Sociales, núm. 12, págs. 81-100. ISSN: 1575-0825, e-ISSN: 2172-3184.

ZICCARDI, A. (2013): "Proyecto IDEAL, Programa URB-AL III de la Comisión Europea. Una nueva estrategia de Gobernanza Local. La intermunicipalidad en América Latina. México: Gobierno del Estado de Michoacán de Ocampo; Uruguay: CLAEH. 2012" en Revista Iberoamericana de Estudios Municipales, año IV, vol. 8. págs. 24-28. 